\title{
IDENTIFICATION OF THE MAPPING MODELS OF THE PLAYERS COOPERATION IN SERVE RECEPTION IN VOLLEYBALL
}

\author{
Leszek Mazur \\ University School of Sport in Wroclaw, Poland \\ ORCID: 0000-0002-0783-3254 | e-mail: leszek.mazur@wszic.pl
}

\begin{abstract}
Ahstract Introduction. Identifying cooperation in team games is a difficult process to implement. Thanks to the development of methods and techniques of game observation, it is possible to reliably and accurately identify and evaluate the actions of players. The collections of various analyzes are used to create pragmatic game models. There are several types of such models. The paper presents models representing effective cooperation in the game on the example of volleyball. Aim of the study. The aim of the study was to identify mapping models of effective cooperation in the game, in the game positioning phase - in the element of receiving-passing the ball (serves). The second goal was to present the differences and similarities between observed teams. Material and methods. The work uses a method called qualitative study of unique cases, the research material consists of the four highest-ranked teams from Rio de Janeiro 2016 Olympic Games. Results. Four different models of cooperation in receiving-passing the ball (serve) were identified. Each of them contains characteristic features visible in the figures. Conclusions. Various models of cooperation have been identified. Each team has a specific model of receiving-passing the ball (serve) due to the spatial flexibility. The models presented in the paper are effective because they show the cooperation of the best teams in the world.
\end{abstract}

Key Worlds volleyball, cooperation, mapping models, service reception, game models, Olympic Games

\section{Introduction}

Nowadays, thanks to the great possibilities and continuous development of methods and techniques of game observation, the development of technology in sport, as well as paying more attention to the processes of monitoring and evaluation of the game, it is possible to more objectively and reliably evaluate players. The analysis covers different elements like: players motor skills, psychological and mental sphere, but most of all - their efficiency in the game. The analysis of the collected data allows for identification of actions taken by the players and assessment of their efficiency. The collections of such analyzes can be used to create various types of game models, which seem to be the best tool for presenting and identifying cooperation in team sports. Game models are based on the praxeology and the theory of sports games. Praxeology is regarded as an applied science, which means that the obtained research results can be used in sports practice and constitute a beneficial value. The praxeological model defined by Pszczołowski (1978) is a complex object that reflects a complex, existing or projected fragment of reality for cognitive purposes. 
In order to best understand the idea of using game models in identifying the processes of action and cooperation in the game, it is necessary to organize their types and ways of using them in practice. Game models are pragmatic models, i.e. models of players' actions, which allow the rationalization of processes aimed at their improvement. Panfil (2006) characterized six types of game models. There are two types of cognitive models: ideal mapping and ideal designing models, as well as two types of practical models: real mapping and real designing models. There are also promotional models (mapping and designing) that are used to improve the image of a sporting event and increase its attractiveness.

The ideal mapping models allow for some kind of re-creation and identification of the actions in the game taken by the observed players - representing the highest possible sports level (championship level). The main characteristic of ideal mapping models is, above all, the lack of influence on the monitored players. These type of models are created without time pressure, and there are no other restrictions on players monitoring when creating them. In addition, the monitoring of activities takes place on the basis of specific efficiency criteria (resulting from game theory and praxeology). Perfect models imitating the game of the best teams are created with the help of the so-called detailed mapping models - that is, various types of activity tables, graphics, charts, etc. Ideal mapping models allow for the identification of actions and cooperation of players in sports teams. Thanks to these models, it is possible to draw conclusions and create rational practical directives, which can then be used in the creation of ideal design models as well as practical (mapping and design) models.

Ideal game-design models are a set of assumptions, rules and conclusions resulting from the praxeology, the theory of the sports game, and above all from the observation of the best teams (championship level) and ideal models reflecting this game. Ideal design models can be helpful in sports practice. Such models are also often used in the development of long-term team and discipline development strategies. It should be noted, however, that the ideal game design models result from the objective and reliable monitoring of the best players and may constitute some kind of pattern or scheme.

Real mapping and designing models are a kind of practical models. This type of models are used in the process of managing various teams. Their characteristic features are the ability to influence the actions of players, and the observation criteria result primarily from the tasks set for the players. Real models are created by constantly comparing the real mapping model with the real designing model. Real models are therefore a kind of a loop, where the design model is subject to observation, and by means of the mapping model, by comparing and evaluating the actions taken, corrections are made to this design model.

In this work, mainly ideal mapping models representing the game of the masters were used. The game at the highest sports level is characterized by the use of the ability to surprise the opponent. All actions taken by the players come down to the element of surprise, so as to be able to achieve the full possibility of acting while achieving the goals. The surprise of the opponent is achieved through the conscious or intuitive use of various solutions (Panfil, 2012). The opponent is surprised by creativity of actions, by the choice (variety) of action or its speed (and change of speed of action). The criteria for assessing creative solving of a situation are, on the other hand, accuracy of action, flexibility or the creation of a new quality. The interoperability models can also be described as flexible. The flexibility of the model is then understood as the ability to adapt the actions taken to the current situation of the game, i.e. in this case to adjust the interaction to the requirement of an effective game. The flexibility of the model can be considered here in three elements. It is: 
- flexible use of various combinations, where players perform various methods of cooperation, adjusting them to a given situation, so as to surprise the opponent and score a point,

- flexible use of the game space, where players interact with each other in different places of the game space, using various methods of interaction,

- flexible differentiation of the speed of cooperation, where the players interact with each other using combinations with different tempo of displaying the ball (1,2 and 3 tempo).

The flexibility of interaction in the offensive game increases the possibilities of surprising the opponent. That is why sports teams, in order to be able to compete effectively, use flexible (differentiated) models of cooperation in the game. The work attempts to show the possibility of formulating models of various manifestations of team synergy occurring in a sports game.

\section{Aim of the study}

The aim of this study was to identify game-mapping models of effective cooperation based on the examination of the links between the skills of players cooperation in the phase of game positioning - serve receive and pass phase, and the effectiveness of male sports teams playing volleyball in the competition classified at the highest level of sports championship. Moreover, the author attempted to present the differences and similarities between identified models.

Due to the main aim of this research it is possible to formulate the following research questions:

1. What are the characteristics of the various models representing the cooperation of players in receivingpassing the ball (serve), due to the criterion of flexibility of cooperation?

2. What are the differences and similarities between the identified models representing the interaction of players in receiving-passing the ball (serve)?

\section{Material and methods}

\section{Research method}

In this research work, a research method called a qualitative study of unique cases was used. This method is an original research procedure that allows for a pragmatic perception of research, as well as a pragmatic perception of its results together with their interdisciplinary dimension (Panfil, Superlak, 2011). The method should be used precisely when analyzing complex, exceptional and unique entities, and such are sports game teams. When identifying the various ways in which players interact, an observation technique was used.

\section{Research tool}

The study used an original observation sheet of cooperation in serve reception in volleyball (Figure 1). The cooperation observation sheet in serve reception is a research tool which aims to graphically identify the interaction between the player passing the ball (i.e. who receives the service) and the player on the field (who makes the second hit - sets the ball). The sheet is a representation of a volleyball court. The line in the middle of the figure (black in bold) is the center line of the court, dividing it into two halves. The bold black lines to the right and left of the center line are the $3 \mathrm{~m}$ lines that separate the frontcourt from the backcourt according to the rules of the game. The sheet marks the place where the receiving player hits the ball, and then the place where the player hits 
the ball. The pitch was divided into 18 equal areas ( $3 \mathrm{~m} \times 3 \mathrm{~m}$ squares). The designated places also allow you to define the division of the court zones, which is in force in the FIVB regulations. Thanks to this, it is visible where on the court the player performs a reception pass and from which zone the ball is played.

MATCH:

Team A

Team B

\begin{tabular}{|l|l|l|l|l|l|}
\hline & & & & & \\
\hline & & & & & \\
\hline & & & & & \\
\hline & & & & & \\
\hline
\end{tabular}

Figure 1. Original sheet for identifying cooperation in serve reception in volleyball

\section{Research material}

The material consists of sports teams playing volleyball at the highest level of classified sport. The research material consists of the teams that took the first four places during the Olympic Games in Rio de Janeiro in 2016. Moreover, these are the teams that are currently in the top positions of the FIVB ranking (data as of 1.08.2018). These teams meet the effectiveness criterion, because the Olympic tournament is one of the most important tournaments in international volleyball competitions (its significance is also confirmed by the maximum number of possible points for the world ranking (100 points for a victory, 90 for 2nd place, etc.) The selected teams are:

- Brazil national team: 1st place in the Olympic tournament (1st place in the FIVB ranking),

- Italy national team: 2nd place in the Olympic tournament (3rd place in the FIVB ranking),

- US national team: 3rd place in the Olympic tournament (2nd place in the FIVB ranking),

- Russia national team: 4th place in the Olympic tournament (5th place in the FIVB ranking).

\section{Description of the research procedure}

The research was conducted by observing the matches played during the volleyball tournament of the Olympic Games in Rio de Janeiro in 2016. Each of the teams was observed during the three matches. Mainly matches from the final stage of the tournament (quarter-final and semi-final matches, as well as the final and the match for 3rd place) or from the group stage, also with teams presenting a high sports level. List of watched meetings: 


\section{Brazil national team:}

- Brazil-USA - Group A match, date: August 11, 2016, result: $1: 3(20: 25 ; 23: 25 ; 25: 20 ; 20: 25)$,

- Brazil-Russia - semi-final on August 19, 2016, score: $3: 0$ (25:21; $25: 20 ; 25: 17)$,

- Brazil-Italy - final, date: August 21, 2016, result: $3: 0$ (25:22; $28: 26 ; 26: 24)$.

\section{Italy national team:}

- Italy-Iran - quarter-final, date: August 17, 2016, results: $3: 0$ (31:29; $25: 19 ; 25: 17)$,

- Italy-USA - semi-final, date: August 19, 2016, result: $3: 2$ (30:28; $26: 28 ; 9: 25 ; 25: 22 ; 15: 9)$,

- Italy-Brazil - final, date: 21.08 .2016 , score: $0: 3(22: 25 ; 26: 28 ; 24: 26)$.

\section{The US national team:}

- USA-Brazil - Group A match, date: August 11, 2016, result: $3: 1$ (25:20; $25: 23 ; 20: 25 ; 25: 20$ ).

- USA-Italy - semi-final, date: August 19, 2016, result: $2: 3(28: 30 ; 28: 26 ; 25: 9 ; 22: 25 ; 9: 15)$.

- USA-Russia - match for 3rd place, date: August 21, 2016, result $3: 2$ (23:25;21:25;25:19; $25: 19 ; 15: 13)$.

\section{The Russia national team:}

- Russia-Poland - group B match, date: August 13, 2016, result: $3: 2$ (25 : 18; $16: 25 ; 25: 18 ; 22: 25 ; 15: 13)$.

- Russia-Brazil - semi-final on August 19, 2016, score $0: 3(21: 25 ; 20: 25 ; 17: 25)$.

- Russia-USA - match for 3rd place, date: August 21, 2016, result $2: 3(25: 23 ; 25: 21 ; 19: 25 ; 19: 25 ; 13: 15)$.

The source of data collection were matches recorded in the form of digital video recordings. All matches were captured with a video camera, placed centrally behind one of the end lines, on the dais, in such a way that the two halves of the volleyball court were visible. The location of the camera while recording matches remained the same throughout the game.

Each of the selected games was observed twice using the observation sheet of cooperation in serve reception (Figure 1) to identify interaction between the receiving and setters. When identifying cooperation in accepting the service, each of the actions observed in the video was recorded on the observation sheet as follows: place where the service was received (the place where the player touched the ball) - marked with a dot, the place where the ball was played (the place where the player touched the ball) - was marked dot. Then the dots were connected with a solid line. Thanks to this, after observing the entire game, a "map" of receiving-passing the ball (service) was created, along with the places where it was played. It should be noted that only passes where the ball was moving towards the net were recorded on the sheet (no passes where the ball was directed backwards, towards the end line or outside the recording area).

\section{Results}

The data collected on the identification sheets for cooperation in receiving-passing the ball (serve) allow for the identification of certain patterns in terms of spatial flexibility. The Brazilian team most often directed the ball to zone III of the pitch. The players of this team tried to direct the ball into the space located as close as possible to the net. In the match which ended with a negative result for this team (Figure 2), the most receptions were directed to the space between the court axis and the border of zones II and III. This space is marked in red. In this game, a second area was also designated, where the service was directed, located in zone III, approx. $1.5 \mathrm{~m}$ from the net, behind the identified first area of the most frequent admissions - passes. In matches that ended with a positive result for this team (figures 3 and 4), the space for receiving the service is larger, it covers mostly zones II and III, 
which proves a high spatial flexibility in their cooperation in receiving-passing the ball (serve), and then effectively creating point situations (these areas are marked in red in the figures). In the match with the Italy national team has also designated an area (marked in green) located on the border of the attack line ( $3 \mathrm{~m}$ line), between zones III and VI.

Match: BRAZII 1-3 USA

BRAZIL

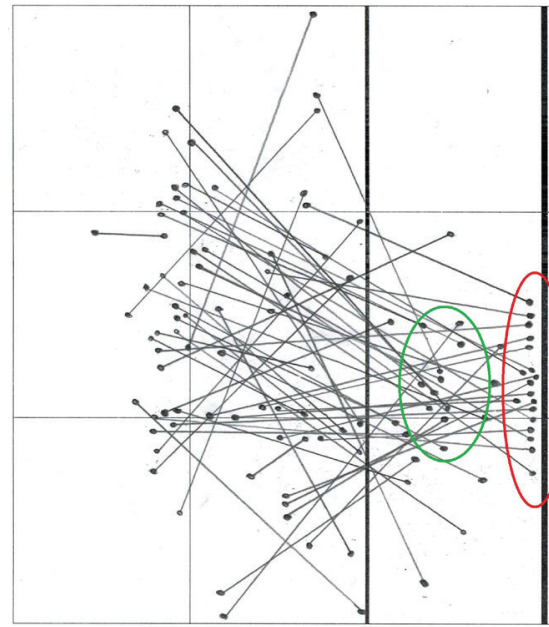

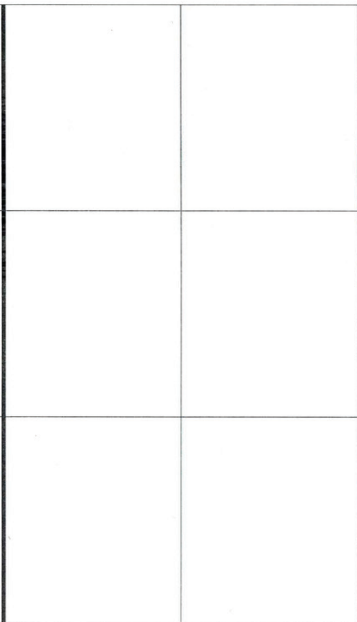

Figure 2. Analysis of cooperation in the field of spatial flexibility in the Brazil-USA - Group A match, result: $1: 3(20: 25 ; 23: 25$; $25: 20 ; 20: 25)$

ITALY

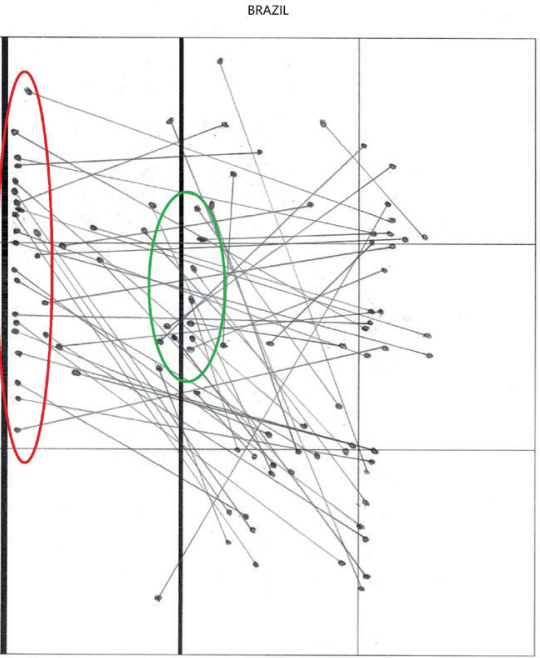

Figure 3. Analysis of cooperation in terms of spatial flexibility in the Brazil-Italy - final match, result: $3: 0(25: 22 ; 28: 26 ; 26: 24)$ 
MATCH: BRAZIL 3-O RUSSIA

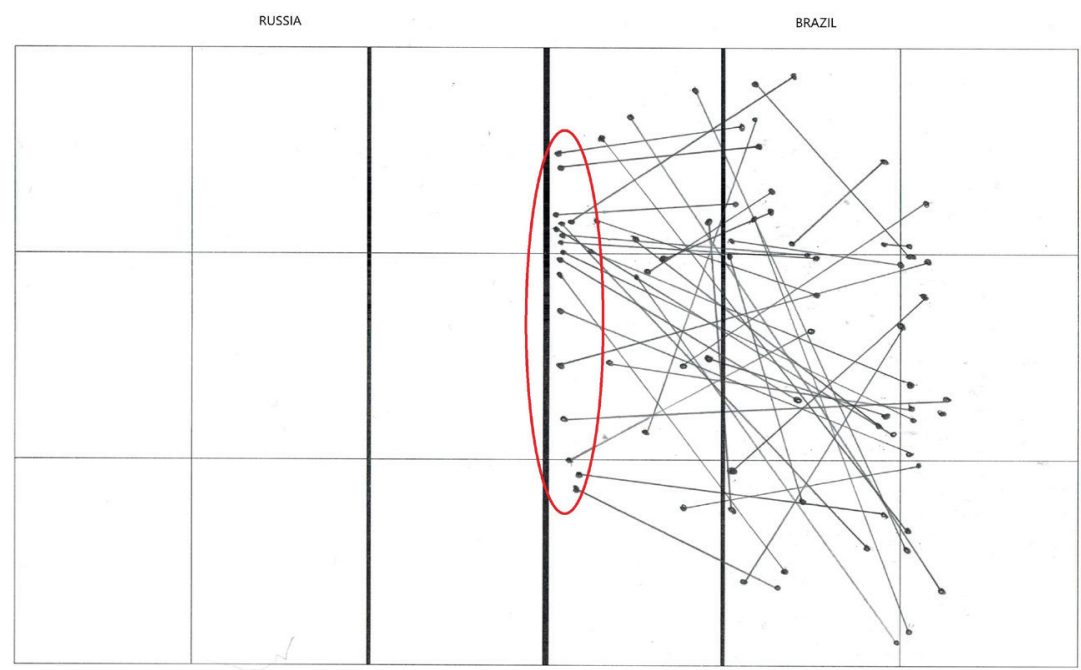

Figure 4. Analysis of cooperation in terms of spatial flexibility in the Brazil-Russia - semi-final match, result: $3: 0(25: 21 ; 25: 20$; $25: 17)$

Analyzing the reception-pass ball (serve) phase of the Italy national team, it is noticeable that generally the first pass was directed to the zone III. In figures 5, 6 and 7, the space marked in red has been identified, which is in close proximity to the net and is located within the axis of the court. This team tries to direct the ball as close as possible to the pitch axis, from where it then creates point situations. During the analysis of selected matches, a second area was designated where the serve reception was directed. This space is located behind the first reception-pass area, approx. $1.5 \mathrm{~m}$ from the net and mostly covers zone III of the court, as well as part of zone II. This space is marked in green in the figures.

By analyzing the spatial flexibility of the United States team, we can determine the areas to which the ball is most often directed after receiving a service. In figures 8,9 and 10 , the area in close proximity to the net, which is located in zone III of the court and also covers a small part of zone II, is marked in red. It was there that the most reception-pass were identified. The green color in the figures also marks the area where some of the balls were directed after the service reception. In all analyzed games, this area is similar and is located on the border of zone II and III of the court, approx. $1.5 \mathrm{~m}$ from the net. It is also worth paying attention to the area marked in blue in Figure 9. In the match with the Italian national team, some of the plays were accepted there, which may be a pattern in the team's tactics. It is noteworthy that a similar area located in this place was identified in the research of Mazur (2017), in a match with the Canadian national team, also played at the Olympic tournament in Rio de Janeiro, where cooperation in the reception-passing of the US team was analyzed. 
ITALY

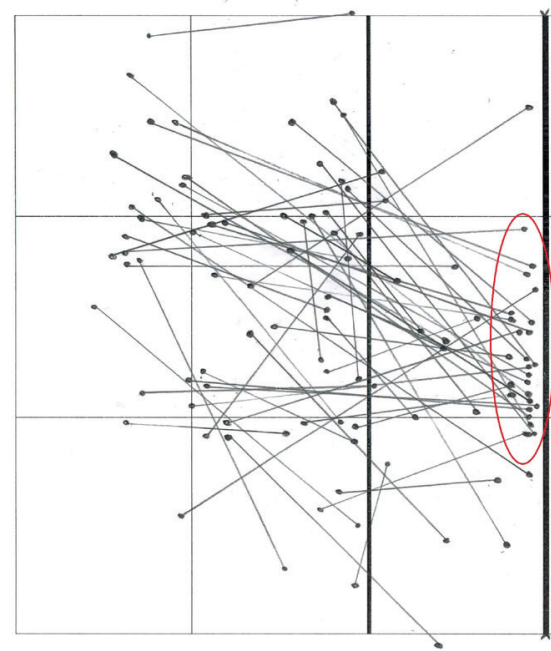

IRAN

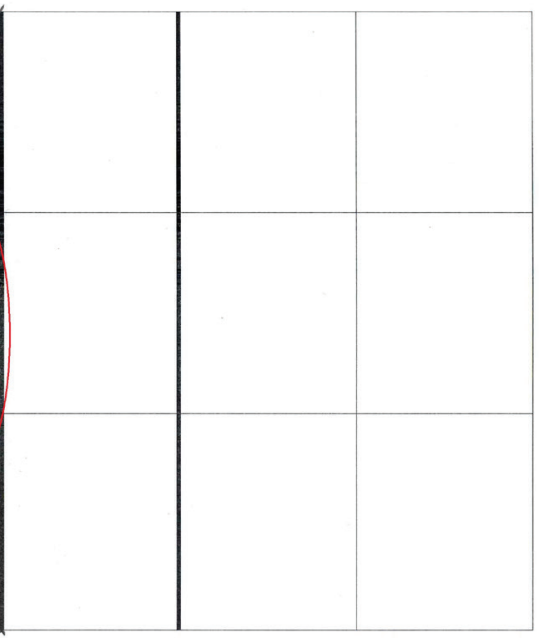

Figure 5. Analysis of cooperation in terms of spatial flexibility in the Italy-Iran - quarter-final match, results: $3: 0(31: 29 ; 25: 19$; $25: 17)$

MATCH: USA 2-3 ITALY

ITALY

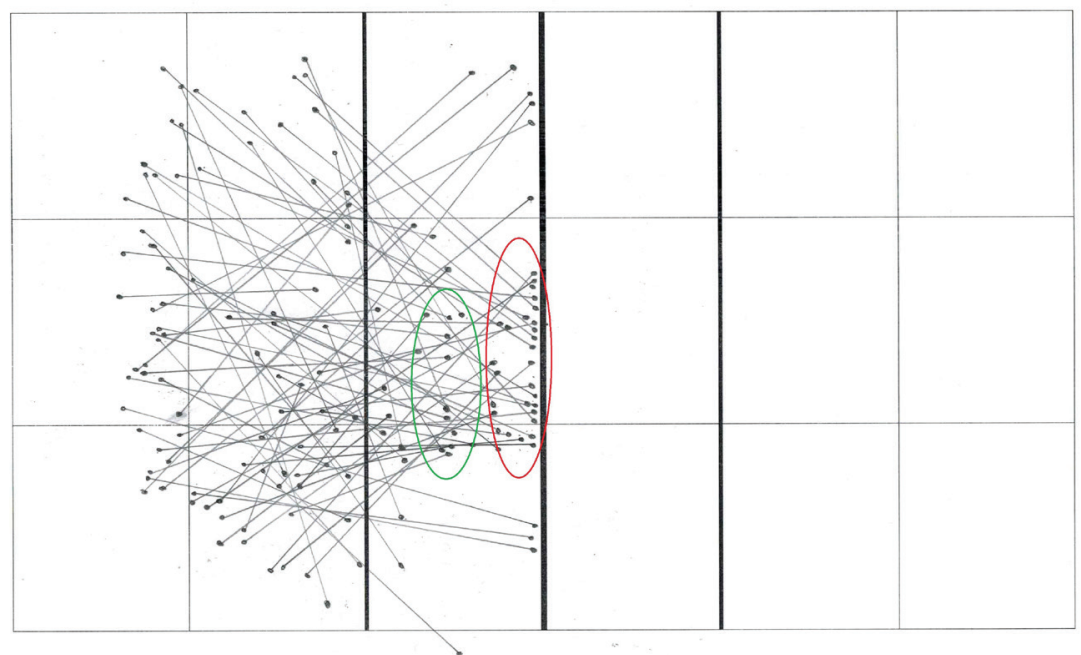

Figure 6 . Analysis of cooperation in the field of spatial flexibility in the Italy-USA - semi-final match, result: $3: 2(30: 28 ; 26: 28$; $9: 25 ; 25: 22 ; 15: 9)$ 
ITALY

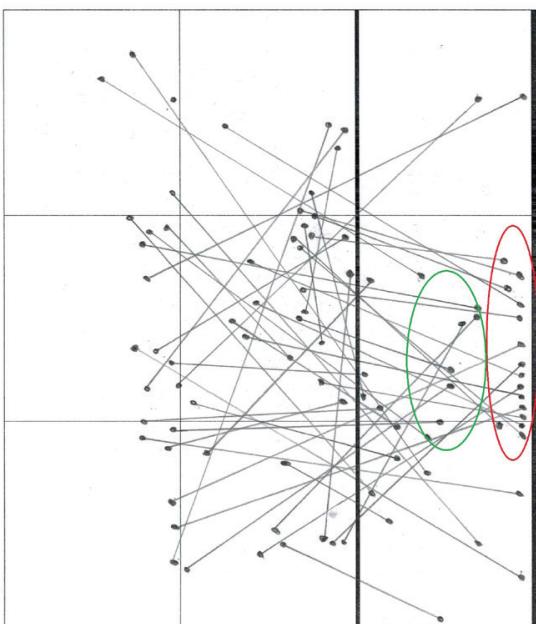

BRAZIL

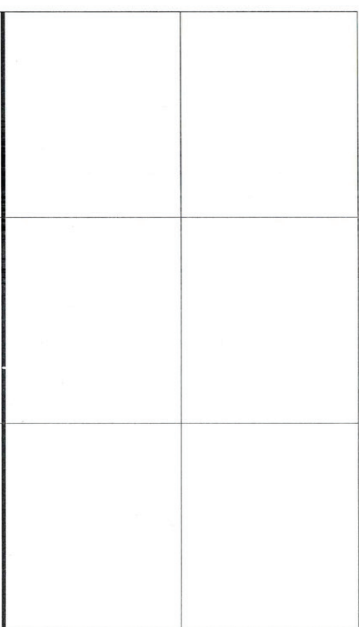

Figure 7. Analysis of cooperation in terms of spatial flexibility in the Italy-Brazil - final match, result: $0: 3(22: 25 ; 26: 28 ; 24: 26)$

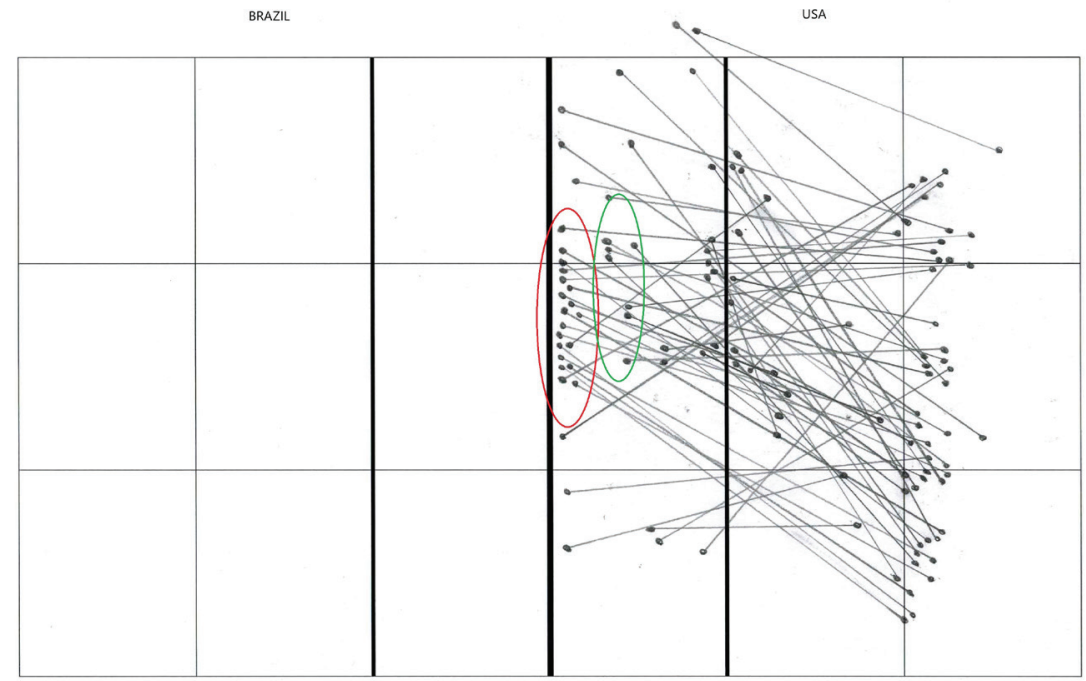

Figure 8. Analysis of cooperation in the field of spatial flexibility in the USA-Brazil - Group A match, result: $3: 1$ (25: 20; $25: 23$; $20: 25 ; 25: 20$ ) 


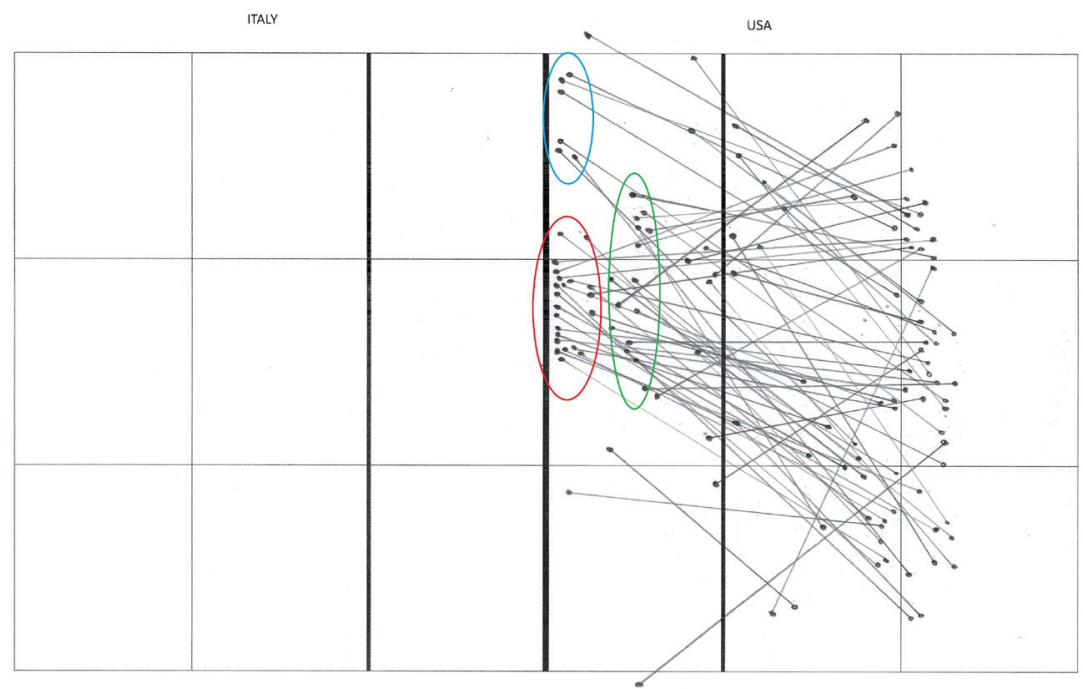

Figure 9 . Analysis of cooperation in the field of spatial flexibility in the USA-Italy - semi-final match, result: $2: 3(28: 30 ; 28: 26$; $25: 9 ; 22: 25 ; 9: 15)$

MATCH: USA 3-2 RUSSIA

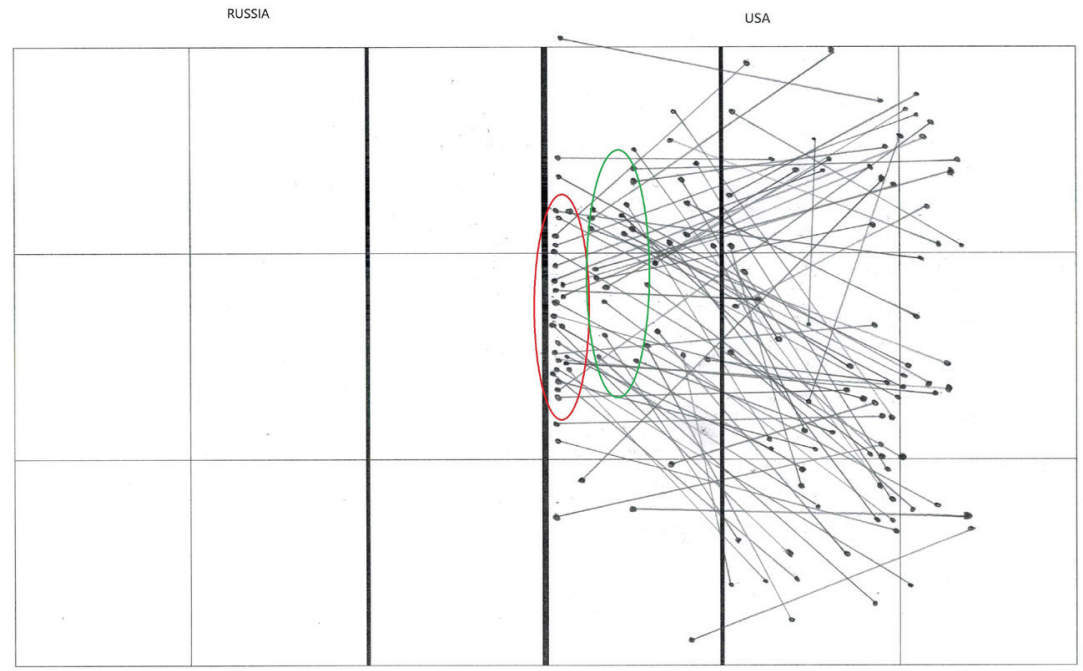

Figure 10. Analysis of cooperation in the field of spatial flexibility in the USA-Russia - 3rd place match, result $3: 2(23: 25$; $21: 25 ; 25: 19 ; 25: 19 ; 15: 13)$ 
The analysis of the spatial flexibility of cooperation in receiving-passing the ball (serve) of the Russian national team allowed for the designation of several zones in this phase of the game. After receiving the service, the most of the balls were directed to the space located in close proximity to the net and between zones II and III of the court. This area is marked in red in figures 11, 12 and 13. Figures 11 and 12 also show the green area to which the serves were also directed. This space is not less than 1.5 meters from the net and is located on the border of zones II and III of the volleyball court. Figure 11 also identified two more smaller areas of reception-pass serves, where the ball was directed in the match with the Brazilian national team, however, the pattern of receiving-passing to this place was not repeated in other observations, which can be treated as a coincidence.

When analyzing the positioning phase in receiving-passing the ball (serves), differences between the teams are visible. Comparing teams due to the spatial flexibility criterion is difficult, because each of them implements their own, unique strategy of cooperation in this phase of the game. Each of the models presented in this research, however, has some specificity that distinguishes them from the others. It should be emphasized that all selected teams try to receive the ball (serve) as close as possible to the net. The model of receiving-passing the ball of the Brazilian national team is characterized by the widest area of cooperation in this phase of the game. The model of receiving-passing the ball of the Russian team, unlike the Brazilian team, is characterized by a narrow area to which the service is directed. It can be seen in the graphics that this team tries to steer the ball more pointly, near the border of II and III pitch zones, focusing more on accuracy. The remaining spaces marked out in the graphics appear irregularly. The greatest similarity among the models of cooperation during the receiving-passing phase was observed among the Italy and US national teams. The players of these teams tried to steer the ball to zone III. The areas indicated in the graphics cover the space both to the right and left of the pitch axis. The reception-pass the ball (serve) models are very similar in these two cases.

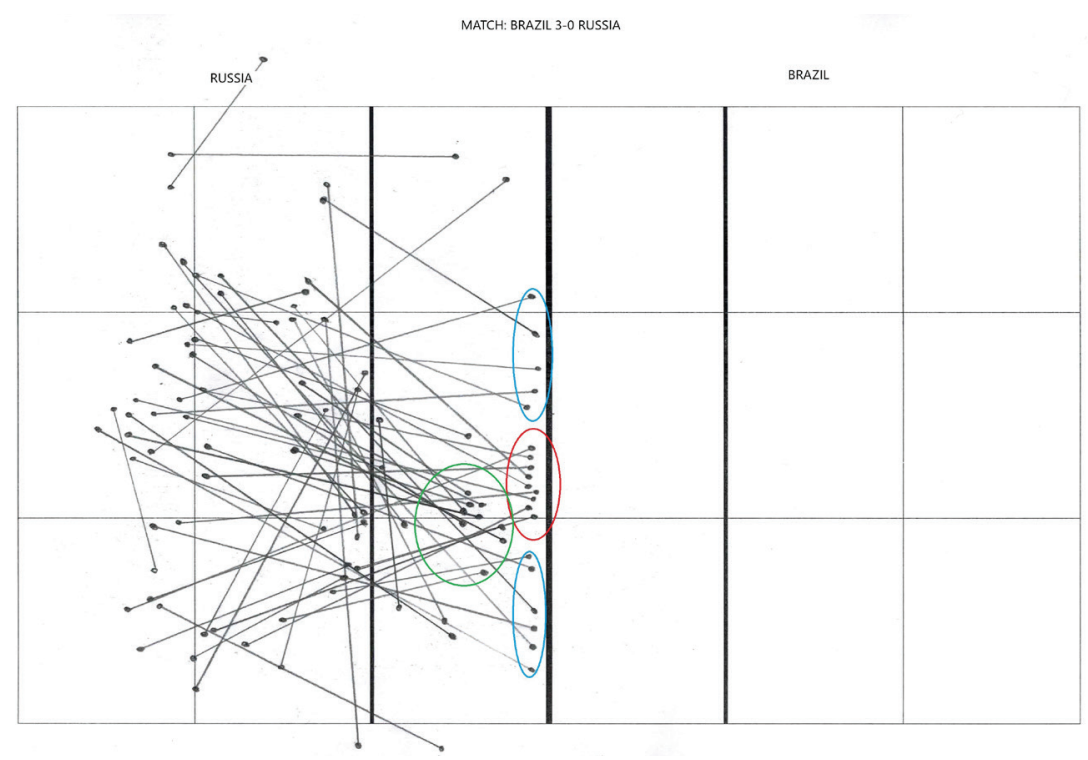

Figure 11. Analysis of cooperation in the field of spatial flexibility in the Russia-Brazil - semi-final match, result $0: 3(21: 25$; $20: 25 ; 17: 25)$ 
MATCH: POLAND 2-3 RUSSIA

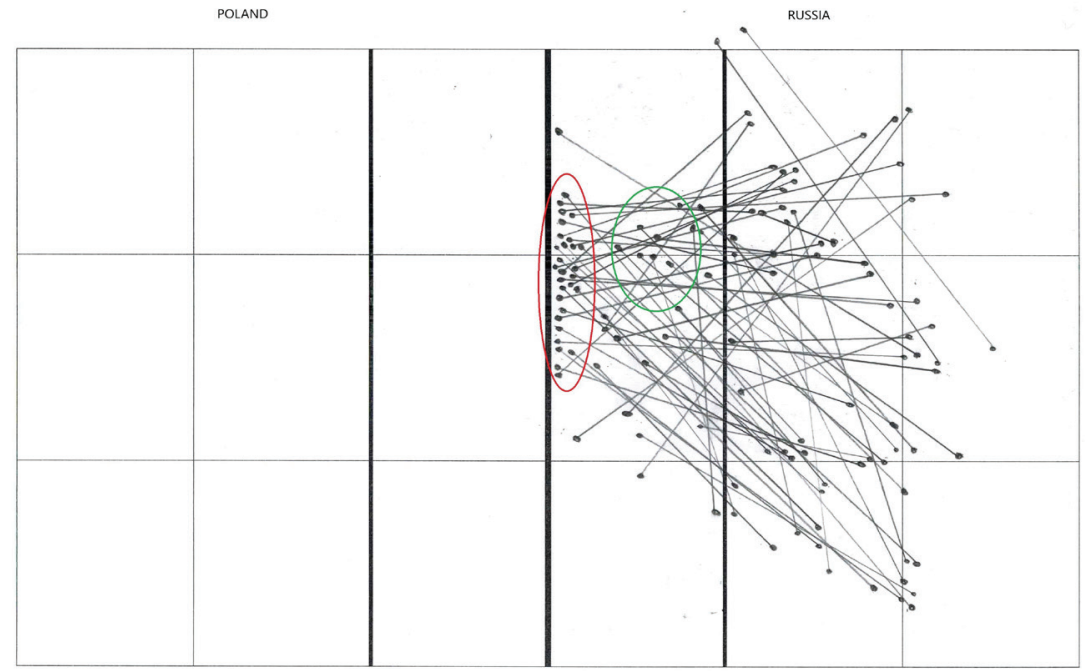

Figure 12. Analysis of cooperation in the field of spatial flexibility in the Russia-Poland - group B match, result: $3: 2$ (25: 18; $16: 25 ; 25: 18 ; 22: 25 ; 15: 13)$

MATCH: USA 3-2 RUSSIA

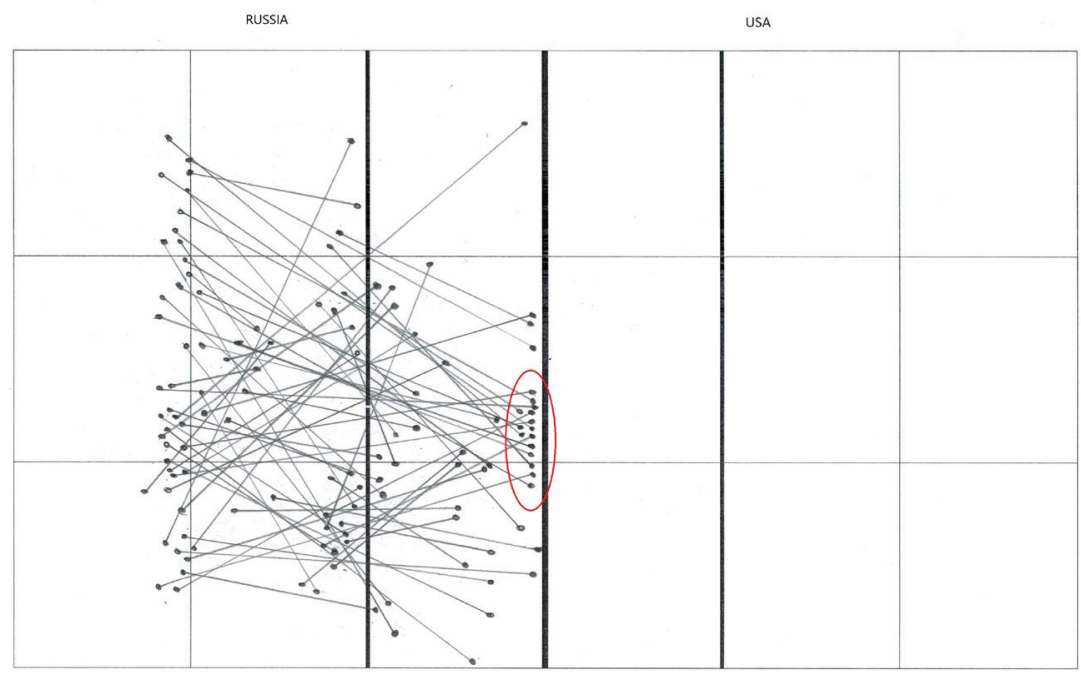

Figure 13. Analysis of cooperation in the field of spatial flexibility in the Russia-USA - 3rd place match, result $2: 3$ (25:23; $25: 21 ; 19: 25 ; 19: 25 ; 13: 15$ ) 


\section{Discussion}

Trying to identify cooperation in team games is very important, but also innovative. Still few scientific works focus on a holistic view of cooperation processes, assessing players usually through the prism of individual actions. Scientific publications are most often based on the assessment of individual activities, referring them to the final result of the game, without taking into account the influence of other team players on enabling these activities to be performed during the game An example may be works such as: Drikos (2018), Hayrinen, Hoivala, Luhtanen (2000), Kountouris, Drikos, Angelonidis, Laios, Kyprianou(2015), Costa Freire (2017), Costa Freire, Evangelista, Pedrosa, Ugrinowitsch, Catro (2018), Pena, Rodríguez-Guerra, Buscà, Serra (2013), Palao, Santos, Urena(2007), Mesquita, César (2007) and many more. The main purpose of this work is to draw attention to cooperation in the game. Identifying the players cooperation allows to look at the team functioning as a one system. Research methods should be sought that will allow for the evaluation and analysis of cooperation in team sports. One of such methods is the presentation of cooperation in the form of mapping models. Thanks to the models, it is possible to actually represent the various ways of cooperation that occur in teams. Some authors have already taken up the issue of identifying cooperation in the form of pragmatic game models.: Panfil Paluszek. (2005), Becella (2005), Nowak (2014), Nowak, Panfil (2012), Mazur, Superlak (2015), Mazur, Superlak (2018) and others. This work is a continuation of this kind of trend in research. The issue of identifying the model of cooperation in the positioning phase of a volleyball game was already undertaken by Mazur (2017). This work is a kind of extension of that data which was published.

An analysis of the spatial flexibility of selected teams allows us to designate areas on the pitch where selected teams most often passed the ball after receiving a service. The main goal of all teams is to direct the ball into a space as close as possible to the net. This is due to the fact that the setters can then surprise their opponent with much greater efficiency, creating various point situations with their teammates. The speed of the combinations performed then is very high, which causes the block and defense of the opponent to be surprised, and thus it is easier to score points. However, differences in the spatial flexibility of the studied interaction among teams were observed. In the presented research results, the Brazilian national team mainly tried to steer the ball into the space located between zones III and II. An interesting fact is that in matches that ended in a positive result for this team, the area to which the ball was directed is larger than the area marked in the match which they lost. This may mean that this team tries to position the game using as much space as possible in order to surprise the opponent by flexible use of combinations in the phase of creating point situations, in different places on the court. Thanks to the large area to which the ball is directed after receiving a service, it is easier to surprise the opponent by using a variety of ways to create point situations at different places on the pitch. However, when the opponent effectively prevents by efficiently performing the service, then the space of cooperation in receiving-passing the ball decreases. In the observed games, areas further away from the net were also designated. They were located mainly in the III zone of the court, near the $3 \mathrm{~m}$ line. These areas differ from one match to the other, but this was due to the quality of the opponent's service, i.e. the scale of its difficulty.

Cooperation in receiving-passing the ball is not always successful, and the ball is not directed to the place chosen by the receiver. The opponent always tries to make the positioning phase of the game as difficult as possible, which is why there are other areas of receiving-passing the ball, located further away from the net, so achieving the goal of surprising the opponent is more difficult. Differences in spatial flexibility between the studied teams were observed in the cooperation of the Russian team. The players of this team try to steer the ball as close as 
possible to the net, but this area is quite small and in all observed games, it was located between the II and III field zones. The space between these two zones is often referred to by discipline experts as the "perfect reception zone" or "zone 0 ". For many years, this place was recognized as the best place to effectively create point situations. It can be assumed that this team is trying to steer the ball into this space, because in the observed games, areas also between these two zones of the court (II and III), but further away from the net, have also been marked. After analyzing these spaces, the direction of receiving-passing the ball by the players of this team is noticeable. The teams from the USA and Italy had the most similar models of cooperation in terms of spatial flexibility. You can see a great similarity in the cooperation of these teams in this phase of the game. Both teams tried to direct the ball as close as possible to the net, into the space close to the court axis, in zone III. Outside this area, both teams have designated areas further away from the net (more than $1.5 \mathrm{~m}$ ), including the area of II and III pitch zones. These teams try to direct the ball towards the axis of the court, which also seems to be the right choice, because then the distance to the individual players performing the attack is comparable, and then the players of these teams can surprise the opponent by choosing the appropriate combinations and players performing them.

\section{Conclusions}

The analysis of the research results allows to conclude that the main goal of the work, which was to identify mapping models of effective cooperation in the game, was achieved. Various models of cooperation have been identified, based on the performance of the top four teams of the 2016 Olympics in Rio de Janeiro in volleyball, in the positioning phase - where cooperation in the element of receiving-passing the service ball was observed. The models presented in the paper could be treated as effective, because they show the cooperation of the best teams in the world in volleyball. It should be emphasized that the work was not intended to assess the effectiveness of individual activities, but to present how the cooperation is actually implemented by the most effective teams competing in this discipline. The obtained research results allow for the formulation of answers to the research questions posed, which can be used as practical directives for other sports teams :

1. Each team has a specific model in receiving-passing the ball (serve) due to the spatial flexibility.

2. All teams try to direct the ball as close as possible to the net.

3. The model representing the reception-pass of the team of Brazil is characterized by a large width of the area to which the ball is directed after the serve reception, the model of the Russian team has the smallest width of the area to which the service is received. The most similar models in the receiving-passing the ball (serve) have the teams of the United States and Italy, which direct the ball around the axis of the court.

\section{Referenences}

Becella, Ł. (2005). Sprawnościowy model tworzenia i wykorzystania sytuacji do zdobycia bramki na ME 2004 w piłce nożnej. In: S. Żak, M. Spieszny, T. Klocek (eds.). Gry zespołowe w wychowaniu fizycznym i sporcie. Studia i Monografie, 33. AWF Kraków.

Costa, G. Freire, A. (2017). High-level female volleyball: analysis of the attack on Superleague Female. Brazilian Journal of Physical Education and Sport, 31 (2), 365-372.

Costa, G.T, Freire, A., Evangelista, B., Pedrosa, G., Ugrinowitsch, H., Catro, H. (2018). Brazilian high-level men's volleyball: characterization of the attack performed by the opposite player. Kinesiology, 50 (2).

Drikos, S. (2018). A longitudinal study of the success factors in high-level male Volleyball. J PANR Journal, June 13. Retrieved from: https://www.panr.com.cy/?p=1731. 
Hayrinen, M., Hoivala, T., Luhtanen, P. (2000). Factors affecting winning in men's international level volleyball. Conference: 5th Annual Congress of the European College of Sport Sciences, vol. Proceedings of the 5th Annual Congress of the European College of Sport Sciences.

Kountouris, P., Drikos, S., Angelonidis, Y., Laios, A., Kyprianou, M.A. (2015). Evidence for differences in men's and women's volleyball games based on skills effectiveness in four consecutive Olympic tournaments. Comprehensive Psychology, 4, art. 9.

Mazur, L. (2017). Identyfikacja modelu efektywnego współdziałania w pozycjonowaniu gry w piłce siatkowej. Quality In Sport, 3 (3), 25-41.

Mazur, L., Superlak, E. (2015). Organizacja i efektywność współdziałania w ataku ze względu na pozycję zawodnika rozgrywającego na boisku w grze w piłkę siatkowa. Rozprawy Naukowe, 51, 118-126.

Mazur, L., Superlak, E. (2018). Identification of mapping models of players cooperation in creating point situations in volleyball depending on setter position. Polish Journal of Sport and Tourism, 25 (2) 25-31.

Mesquita, I., César, B. (2007): Characterization of the opposite player's attack from the opposition block characteristics. An applied study in the Athens Olympic Games in female volleyball teams. International Journal of Performance Analysis in Sport, 7 (2), 13-27.

Nowak, M. (2014). Umiejętność pozycjonowania gry w tenisie ziemnym. Pragmatyczne studium indywidualnych przypadków. Rozprawy Naukowe, 44. AWF Wrocław, 85-92.

Nowak, M., Panfil, R. (2012). Scoring abilities in the game of tennis (pragmatic study of rare cases), Human Movement, 13 (4), $313-322$.

Palao, J.M., Santos, J.A., Urena, A. (2007). Effect of the manner of spike execution on spike performance in volleyball. International Journal of Performance Analysis in Sport, 7 (2), 126-138.

Panfil, R. (2006). Prakseologia gier zespołowych. Studia i Monografie, 82. Wrocław.

Panfil, R. (2012). Pragmatyka współdziałania w grach sportowych. Wrocław: Wyższa Szkoła Zarządzania i Coachingu.

Panfil, R., Paluszek, K. (2005). Sprawnościowe modele działań graczy w futsalu. In: S. Żak, M. Spieszny, T. Klocek (eds.), Gry zespołowe w wychowaniu fizycznym i sporcie. Studia i Monografie, 33. AWF Kraków.

Panfil, R., Superlak, E. (2011). Strategie wykorzystania umiejętności współdziałania w kreowaniu sytuacji punktowych (Pragmatyczne studium gry w piłkę siatkowa). Antropomotoryka, 21 (53), 110-119

Pena, J., Rodríguez-Guerra, J., Buscà, B., Serra, N. (2013). Which skills and factors better predict winning and losing in high-level men's volleyball?. Journal of Strength and Conditioning Research, 27 (9), 2487-2493.

Pszczołowski, T. (1978). Mała encyklopedia prakseologii i teorii organizacji. Wrocław: Ossolineum.

Cite this article aS: Mazur, L. (2021). Identification of the Mapping Models of the Players Cooperation in Serve Reception in Volleyball. Central European Journal of Sport Sciences and Medicine, 3 (35), 71-85. DOI: 10.18276/cej.2021.3-07. 